\title{
Enzymes modulation by dried grape pomace from the manufacture of wines and juices
}

\author{
Juliana Mesquita Freire ${ }^{\circledR 1^{*}}$, Amanda Ribeiro Barroso ${ }^{1}$, Amanda Araújo de Assis ${ }^{1}$, \\ Bruna Helena Texeira ${ }^{1}$, Jonatas Henrique Guimarães Braga ${ }^{2}$, \\ Daniela Aparecida Oliveira' ${ }^{1}$, Mariana Aparecida Braga ${ }^{1}$, Silvana Marcussi ${ }^{1}$ \\ ${ }^{1}$ Biochemistry Laboratory, Department of Chemistry, Federal University of \\ Lavras - Lavras-MG, Brazil, ${ }^{2}$ Meat and Fish Laboratory Laboratory, Department \\ of Food Science, Federal University of Lavras - Lavras-MG, Brazil
}

\begin{abstract}
The processing of grapes for the manufacture of juices and wines, generates large quantities of by-products rich in metabolites with antioxidant, antimicrobial, anti-inflammatory and cicatrizing activities. The high homology between human enzymes and snake venoms makes the latter valuable laboratory tools for the study of pathophysiological processes. Proteases and phospholipases $\mathrm{A}_{2}$ act in processes related to hemostasis and inflammatory response. Thus, in this work, dried pomace obtained from grape (Isabel, Niagara, Bordô, BRS Violeta and Blend cultivars) processing were evaluated on phospholipase, proteolytic, hemolytic and thrombolytic activities induced by snakes venoms and the content of phenolic compounds and minerals was evaluated. The dried pomace exerted inhibitory and potentiating actions in all analyzed activities. The enzymatic modulators present in the evaluated dried pomace have potential for therapeutic use, although their broad characterization is still necessary, in order to define adequate amounts and formulations to obtain efficacy and safety in their use.
\end{abstract}

Keywords: Grape extracts. Industrial wastes. Phenolic compounds. Protease modulators. Phospholipase $\mathrm{A}_{2}$ modulators.

\section{INTRODUCTION}

The agro-industry produces large amounts of waste that are added to raw material waste throughout production and consumption. According to the Food and Agriculture Organization of the United Nations (Organização das Nações Unidas para a Alimentação e Agricultura, 2011), food waste amounts to 1.3 billion tons per year, which accounts for $40-50 \%$ of the production of vegetables and fruits. These are sources of organic

*Correspondence: J. M. Freire, Biochemistry Laboratory, Department of Chemistry, Federal University of Lavras, University Campus, CP: 3037, Lavras 37200-000, Brazil. Telefax number: +55-35-3829-1271. Tel.: +5535-3829-1273. E-mails: Juliana.freire@dqi.ufla.br, barrosobioufla@gmail. com, amanda.araujo@quimica.ufla.br, bruna13helena@hotmail.com, jonatas.braga1@engalimentos.ufla.br,_danioliveira.ufla@hotmail.com, marybraga07@yahoo.com.br,marcussi@dqi.ufla.br material, rich in phenolic compounds, fiber, vitamins and minerals. According to Botella et al. (2007) and Kammoun et al. (2008), the agro-industrial residues are important in the production of substrates of high added value, which can have nutritional, therapeutic and cosmetic application.

According to Embrapa, grape production in Brazil in 2012 reached about 1.5 million tons. The residues of the grapes used for winemaking are equivalent to $20 \%$ of the weight of the grapes and the residues from the production of grape juice to 25\% (Mello, Silva, 2014). These residues represent a rich source of several high value products such as citric acid, grape seed oil, hydrocolloids and dietary fibers, and phenolic compounds (Rockenbach et al., 2011). 
Phenolic compounds are natural antioxidants that act inactivating the reactive species, which are responsible for the development of various chronic diseases. Grapes are one of the largest sources of phenolic compounds. Simple phenolic are derivates of hydroxycinnomic and p-hydroxybenzoic acid (Ali et al., 2010). However, polyphenols (proanthocyanidins, flavonoids and stilbenes) are the most important class of biologically active in grapes. Most of the flavonoids are found in grape skin, however about $60 \%$ of total polyphenols are found in grape seeds (Abe et al., 2007; Ali et al., 2010; Branan, 2008; Babbar et al., 2011). During wine processing large amounts of proanthocyanidins, pyranoanthocyanins and oligostilbenes are extracted, but for the production of grape juice, only a few amounts of anthocyanins remain in the product (Sun et al., 2005; Capanoglu et al., 2013). Nevertheless, about $70 \%$ of phenolic compounds remain in the pomace (product of wine/ grape juice processing), which becomes a source of phytochemical extraction with biological activities to be explored by the pharmaceutical, cosmetic and food industries (Fontana et al., 2013; Georgiev et al., 2014).

Phenolic compounds have been investigated as enzymatic modulators for therapeutic applications in the prevention and treatment of various diseases. In this context, snake venoms, mainly composed of enzymes such as phospholipases $\mathrm{A}_{2}\left(\mathrm{PLA}_{2}\right)$, metalloproteases, serine proteases, hyaluronidases, disintegrins and L-amino acid oxidases that affect vital physiological functions altering hemostasis, inflammatory and immunological response, characterize valuable tools for the evaluation of enzymatic modulators. Various enzymes, such as $\mathrm{PLA}_{2}$ and proteases present in snake venoms show functional and structural homology with enzymes present in the human body, enabling similarities between the inhibition of enzymes resulting from venoms and the likely effects on human endogenous enzymes (Berling; Isbister, 2015).

Dried grape pomace may be an inexpensive source of phytochemical extraction with biological activities to be explored by the pharmaceutical, cosmetic and food industries (Fontana et al., 2013). However, there are few studies involving natural compounds generated in large scale as industrial waste, configuring a vast field to be scientifically explored. In this way, the objective of this work was to evaluate the action of dried pomace from grape processing on the activity of $\mathrm{PLA}_{2} \mathrm{~s}$ and proteases with action on hemostasis and inflammatory response.

\section{MATERIAL AND METHODS}

Pilot tests were performed with the objective of defining the most suitable venoms for the induction of the proposed activities and the minimum doses inducing each effect, as described in the literature. The experiments with use of human blood were conducted in accordance with the standards of the Ethics Committee on Human Research (COEP) from Federal University of Lavras.

\section{Grape extract obtainment}

The grapes of Bordô, BRS Violeta, Isabel and Niagara cultivars and Blend (combination of cv. Violeta and Niagara), acquired in the municipality of Poços de Caldas, were washed and sanitized with $200 \mu \mathrm{L} . \mathrm{L}^{-}$ ${ }^{1}$ sodium dichloroisocyanurate for 15 minutes. Grape juices were made with Bordô, Blend and Isabel cultivars and the wines were made with BRS Violeta, Isabel and Niagara cultivars.

The processing pomace was weighed, dried in an oven at $45^{\circ} \mathrm{C}$ until constant weight and ground to obtain the respective dried pomace.

\section{Mineral content}

The minerals analyzed were calcium, magnesium, manganese and zinc. The samples were analyzed in extracts obtained by nitric-perchloric acid digestion and readings were performed in atomic absorption spectrophotometer (Malavolta et al., 1997).

\section{Content of phenolic compounds}

The total phenolic compounds were dosed in a spectrophotometer $(750 \mathrm{~nm})$ using the Folin Ciocateau reagent. The results were expressed as $100 \mathrm{~g}^{-1}$ gallic acid equivalents (Singleton, Rossi, 1965).

\section{Antioxidant activity determination}

The electron donation ability of the obtained dried grape pomace was measured through bleaching the DPPH radical according to the method of Rufino et al. (2007). The activity was expressed as IC50 (mg.L $\left.\mathrm{L}^{-1}\right)$, the concentration required to cause a 50\% DPPH inhibition. A lower IC50 value corresponds to a higher antioxidant activity. 
In the b-carotene/linoleic acid system, antioxidant capacity was determined by measuring the inhibition of the volatile organic compounds and the conjugated diene hydroperoxides arising from linoleic acid oxidation according to the method of Rufino et al. (2006). The activity was expressed as the percentage of inhibition of linoleic acid oxidation.

\section{Proteolysis activity on casein substrate}

The proteolysis activity on casein was performed according to Van Der Walt and Joubert (1971) with adaptations to solid medium. The protein substrate was dissolved $1 \%$ in $0.1 \mathrm{M}$ Tris- $\mathrm{HCl}$ solution $\mathrm{pH} 9.0$ and embedded in an agar gel $(0.1 \%)$ which was poured into petri dishes at $45^{\circ} \mathrm{C}$ (Oliveira et al., 2015). Holes were made for sample application. For controls, Bothrops moojeni, B. jararaca and B. atrox venoms $(30 \mu \mathrm{g})$ were used. Samples of the dried pomace were incubated with 1:1, 1:2, 1:4, 1:8 and 1:12 ratios (venom: extract; $\mathrm{w}: \mathrm{w})$ in a heating bath for 30 minutes at $37^{\circ} \mathrm{C}$. Plates remained in cell culture chamber at $37^{\circ} \mathrm{C}$ for 12 hours. The gels were stained in black starch solution (1\%) and decolorized in $20 \%$ acetic acid solution. The activity was quantified by the measurement $(\mathrm{mm})$ of the diameter of the translucent halos and the results expressed in percentage, considering the controls containing only the venoms as $100 \%$ of activity.

\section{Thrombolysis activity}

Thrombolytic activity was evaluated in human blood clots formed in vitro, according to the methodology described by Cintra et al. (2012). Samples of the dried pomace were incubated for 30 minutes at $37^{\circ} \mathrm{C}$ with $B$. moojeni and Lachesis muta muta venoms $(40 \mu \mathrm{g})$, in 1:2, 1:4 and 1:8 ratios (venom: extract; w:w) and then applied on the thrombi. Plates remained in cell culture chamber at $35^{\circ} \mathrm{C}$ for 24 hours. Controls were performed with PBS (negative control), pure venoms and pure dried pomace. The thrombolytic activity was quantified by the measurement of the volume of fluid released by the thrombi and the values converted in percentage. Being the controls, containing only the venoms, considered as $100 \%$ of activity and the values obtained in the negative control subtracted from the others.

\section{Fibrinogenolysis activity}

To visualize this activity $12 \%$ polyacrylamide gel electrophoresis (m: v) was used according to Laemmli (1970). Previous incubation of B. moojeni and B. atrox venoms $(50 \mu \mathrm{g})$ with dried pomace at the ratios $1: 4$ and 1:8 (venom: extract; w:w) was performed for 30 minutes at $37^{\circ} \mathrm{C}$. Then fibrinogen was added to the samples and they remained under the same incubation conditions for another 90 minutes. The migration profile of the $\alpha, \beta$ and $\gamma$ chains of fibrinogen molecules and their fragmentations were observed after staining of the gels with coomassie blue and discoloration with $20 \%$ acetic acid.

\section{Phospholipase and hemolysis activities}

Phospholipase $\mathrm{A}_{2}\left(\mathrm{PLA}_{2}\right)$ and hemolytic activities were assessed as described by Gutiérrez et al. (1988), with the use of egg yolk for $\mathrm{PLA}_{2}$ activity and erythrocytes for hemolytic activity. $\mathrm{PLA}_{2}$ inhibition tests were carried out using venoms from $B$. atrox, $B$. jararaca and $B$. jararacussu and for hemolysis tests the use of $B$. moojeni and $B$. jararacussu venoms was standardized. The venoms were incubated with different ratios of dried pomace for 30 minutes at 37 ${ }^{\circ} \mathrm{C}$. Then, they were poured into the gel orifices. The gels were placed in a cell culture chamber for 12 hours at $37^{\circ} \mathrm{C}$. The diameters of the translucent halos formed around the gel orifice were measured (millimeters) and expressed in percentage of activity, considering the controls containing only venoms as $100 \%$ of activity.

\section{Analysis of results}

The results were presented as means \pm standard deviation obtained in three independent assays where the samples were evaluated in triplicate. In order to determine the significance of caseinolytic, thrombolytic, phospholipase and hemolytic activities, the analysis of variance was used and considered significant for the effects of inhibition or potentiation, with values $15 \%$ lower or higher, respectively, compared to those obtained in the controls containing only venoms (100\% activity).

\section{RESULTS AND DISCUSSION}

Snake venoms have proteases that affect the blood clotting cascade and are divided into metalloprotease and serine protease. Metalloproteases are involved in the 
hemorrhagic process, in edema formation, hypotension, hypovolemia, as well as in inflammation and necrosis. In hemostasis, they act by degrading or activating coagulation factors, for example, breaking the terminal $\mathrm{C}$ regions of the $\alpha, \beta$ and $\gamma$ chains of fibrinogen molecules into fragments, preventing the activation of thrombin, as well as preventing their activation when they act by depleting factors of coagulation cascade (Sajevic et al., 2011). Serine proteases act on the components of blood degradation and activation that are involved in coagulation and fibrinolysis, activating the kallikrein/ kinin system or affecting platelet aggregation (Birrel et al., 2007).

$\mathrm{PLA}_{2} \mathrm{~S}$ are enzymes that specifically hydrolyze the sn-2 ester bond of 3-sn membrane glycerophospholipids, generating lysophospholipids and free fatty acids, which themselves cause considerable cell membrane damage. In addition, they exhibit wide varieties of pharmacological effects such as neurotoxicity, cardiotoxicity, myotoxicity, as well as necrotic, anticoagulant, hypotensive, hemorrhagic and edematogenic. The inflammatory response and clotting cascade activation result from eicosanoid production generated by the action of cyclooxygenases on arachdonic acid, which results from phospholipids hydrolysis (Leanpolchareanchai et al., 2009).

Several works have also reported natural phenolic compounds as inhibitors of snake venoms $\mathrm{PLA}_{2} \mathrm{~s}$ and proteases (Leanpolchareanchai et al., 2009; Pereañez et al., 2011). The phenolic compounds with a reactive formyl group may easily interact with the toxins (enzymes/ proteins) present in snake venom through chelation or chemical modification. Furthermore, there are a number of mechanisms by which phenolic compounds may act as anti-snake venom: via free radical scavenging, hydrogen donation, singlet oxygen quenching, metal ion chelation $\left(\mathrm{Zn}^{2+}\right.$ and $\mathrm{Ca}^{2+}$, essential for the metalloproteases and $\mathrm{PLA}_{2}$ activity) or as substrates for superoxide attack (Alam et al., 2016).

Grapes are one of the richest sources of phenolic compounds and more than $70 \%$ remain in the pomace. According to Table I, it can be observed that the dried pomace of cultivars Violeta and Isabel presented the highest and lowest content of phenolic compounds, respectively. Blend, a combination of cv. Violeta and

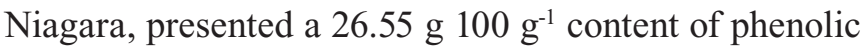
compounds, an intermediate value when compared to the contents presented by the cv that compose it. These findings are related with reports of grape cultivars around the world (Negro et al., 2003; Bozan et al.,
2008; Brannan, 2008) and the most common flavonoids found in grapes are anthocyanins, flavanols (catechin, epicatechin and proanthocyanidins) and flavonols (quercetin, kaempherol and myricetin) and many in the form of gallate ester or glycosides (Cantos et al., 2002; Brannan, 2008; Georgiev et al., 2014)

Studies by Soares et al. (2008) on the phytochemical profile of grape hulls describe that the Niagara cultivar presented higher contents of phenolic compounds than the Isabel cultivar. Vilas Boas et al. (2014) analyzed the content of phenolic compounds of grape juice of the cultivars Violeta, Bordô and Isabel in different storage times and concluded that the Violeta cultivar presented the highest content of these compounds followed by Bordô cultivar, with the Isabel cultivar presenting the lowest. All these results are in agreement with those found in the present study.

The high concentrations of phenolic compounds and the variation of these concentrations among dried grape pomace from different cultivars show that studying the product of wine/grape juice processing is very important.

The antioxidant activity of dried pomace, determined as DPPH radical-scavenging ability, ranges from 0.66 to $2.88 \mathrm{mg} . \mathrm{L}^{-1}$, expressed as EC50 (Table I). The highest and lowest antioxidant activity were found for Violeta and Niagara dried pomace, respectively. In the $b$-carotene/linoleic acid system, the oxidation of linoleic acid produces free radicals that will be oxidized by the highly unsaturated b-carotene. However, the presence of antioxidants could prevent the bleaching of $b$-carotene due to their ability to neutralize the free radicals. Table I shows the percentage of inhibitory activity of dried grape pomace. The highest and lowest antioxidant activity were found for Blend and Niagara dried pomace, respectively. The Isabel dried pomace was not able to protect the linoleic acid from oxidation, but it was able to inactivate the free radical as shown by the DPPH test. High positive correlations between the phenolic compounds and antioxidant activity were observed for dried grape pomace. Similar findings have been reported by several authors (Bozan et al., 2008; Rockenbach et al., 2011; Georgiev et al., 2014; Farhadi et al., 2016).

Hence, the investigation of the interaction between minerals and snake venoms seems to be necessary because minerals are molecules that are closely linked to the performance of enzymatic functions present in organisms. They act as sources 
Enzymes modulation by dried grape pomace from the manufacture of wines and juices

TABLE I - Macronutrient contents (Ca and $\mathrm{Mg}$, expressed in $\mathrm{g} 100 \mathrm{~g}^{-1}$ ), micronutrients ( $\mathrm{Mn}$ and $\mathrm{Zn}$ expressed in mg Kg $\mathrm{K}^{-1}$ ) total

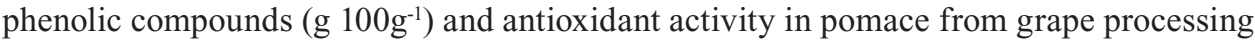

\begin{tabular}{|c|c|c|c|c|c|c|c|}
\hline \multirow{2}{*}{$\begin{array}{l}\text { Grape } \\
\text { cultivars }\end{array}$} & \multicolumn{2}{|c|}{ Macronutrient } & \multicolumn{2}{|c|}{ Micronutrient } & \multirow{2}{*}{$\begin{array}{l}\text { Phenolic } \\
\text { compounds }\end{array}$} & \multirow{2}{*}{$\begin{array}{c}\text { DPPH } \\
\left(\mathbf{m g} \cdot \mathrm{L}^{-1}\right)\end{array}$} & \multirow{2}{*}{$\begin{array}{c}\beta \text {-carotene/ } \\
\text { linoleic acid (\%) }\end{array}$} \\
\hline & $\mathrm{Ca}$ & Mg & Mn & Zn & & & \\
\hline Bordo & $1.03 \pm 0.01$ & $0.11 \pm 0.01$ & $40.1 \pm 0.33$ & $17.72 \pm 0.18$ & $26.20 \pm 2.73$ & $0.90 \pm 0.07$ & $60.80 \pm 4.29$ \\
\hline Isabel & $0.72 \pm 0.02$ & $0.10 \pm 0.03$ & $1.70 \pm 0.96$ & $9.99 \pm 0.30$ & $11.57 \pm 5.47$ & $2.20 \pm 0.34$ & ND \\
\hline Violeta & $0.56 \pm 0.02$ & $0.09 \pm 0.02$ & $18.33 \pm 1.03$ & $10.2 \pm 0.15$ & $34.18 \pm 3.68$ & $0.66 \pm 0.01$ & $51.86 \pm 6.64$ \\
\hline Niagara & $0.64 \pm 0.01$ & $0.07 \pm 0.02$ & $34.9 \pm 0.89$ & $35.38 \pm 1.98$ & $16.18 \pm 2.69$ & $2.88 \pm 0.40$ & $8.71 \pm 1.60$ \\
\hline Blend & $0.78 \pm 0.02$ & $0.09 \pm 0.02$ & $17.81 \pm 0.47$ & $25.37 \pm 1.03$ & $26.55 \pm 3.07$ & $1.64 \pm 0.21$ & $75.48 \pm 9.38$ \\
\hline
\end{tabular}

Data represent means \pm standard deviation of quantifications performed in triplicate.

ND: Not detectable.

of enzymatic cofactors or ligands of target molecules of enzymes, making them more accessible to the toxin attack. The availability of zinc and calcium ions may interfere with proteolytic and hemorrhagic activities and the stability of hemorrhagic toxins in aqueous solutions (Bjarnason, Fox, 1994). According to Miele et al., (1990), grapes are rich in mineral compounds, with high $\mathrm{Ca}, \mathrm{Mg}, \mathrm{P}$ content and lower concentrations of $\mathrm{Zn}, \mathrm{Mn}, \mathrm{Fe}$ and $\mathrm{Cu}$. The same can be observed in the present study in which the contents of $\mathrm{Ca}$ and $\mathrm{Mg}$ were higher than the contents of $\mathrm{Zn}$ and Mn. The dried pomace of the cultivars with the highest and lowest contents of the evaluated minerals were Niagara and Isabel, respectively. The same was observed for the content of zinc ions in the dried pomace. In relation to the calcium ions, a higher content is observed for the Bordô dried pomace (Table I). Thus, the dried pomace may provide higher concentrations of divalent ions, increasing the activity of the proteases.

The highest proportions of the dried pomace evaluated were able to partially inhibit the proteolysis activity of the Bothrops moojeni and B. atrox venoms (Figure $1 \mathrm{~A}$ and $\mathrm{B} ; \mathrm{C}$ and D) on the casein substrate. Bordô dried pomace, in all ratios, was able to inhibit the activity induced by the B. atrox venom (Figure 1D). Niagara and Blend dried pomace in the highest ratio (1:12) were able to inhibit $40 \%$ of the proteolysis induced by the same venom (Figure 1C and D). However, Niagara, Bordô,
Violeta and Blend dried pomace exerted potentiation on the activity induced by $B$. jararaca venom, in different proportions (Figure 1E and F). In particular, the Bordô and Violeta dried pomace increased proteolysis activity by $30 \%$ (Figure $1 \mathrm{~F}$ ).

Dried pomace incubated with $B$. moojeni and $B$. atrox venoms protects the fibrinogen chains, which may act as inhibitors of fibrinogenolytic proteases, through various mechanisms, or bind to fibrinogen molecules in order to protect their structure, thus preventing effects of toxins on blood clotting (Figure 1G). This result corroborates those found by Strauch et al. (2013), in which Humirianthera ampla extract, rich in phenolic compounds, was able to inhibit the fibrinogenolytic activity of $B$. atrox, $B$. jararaca and $B$. jararacussu venoms.

Studies have shown that the methanolic extract of the Vitis vinifera L. seed inhibited the proteolytic and fibrigenolytic activities induced by the Echis carinatus venom in a dose-dependent manner (Mahadeswaraswamy et al., 2008). These data can be correlated with those obtained in the present work, in which the five dried pomace, in the highest ratios, inhibited the proteolytic activity of $B$. atrox and $B$. moojeni venoms.

According to Pithayanukul et al. (2009), the ethanolic extract of Mangifera indica L. and the phenolic pentagalloylglucopyranose isolated from it, exhibited dose-dependent inhibitory effects on the 

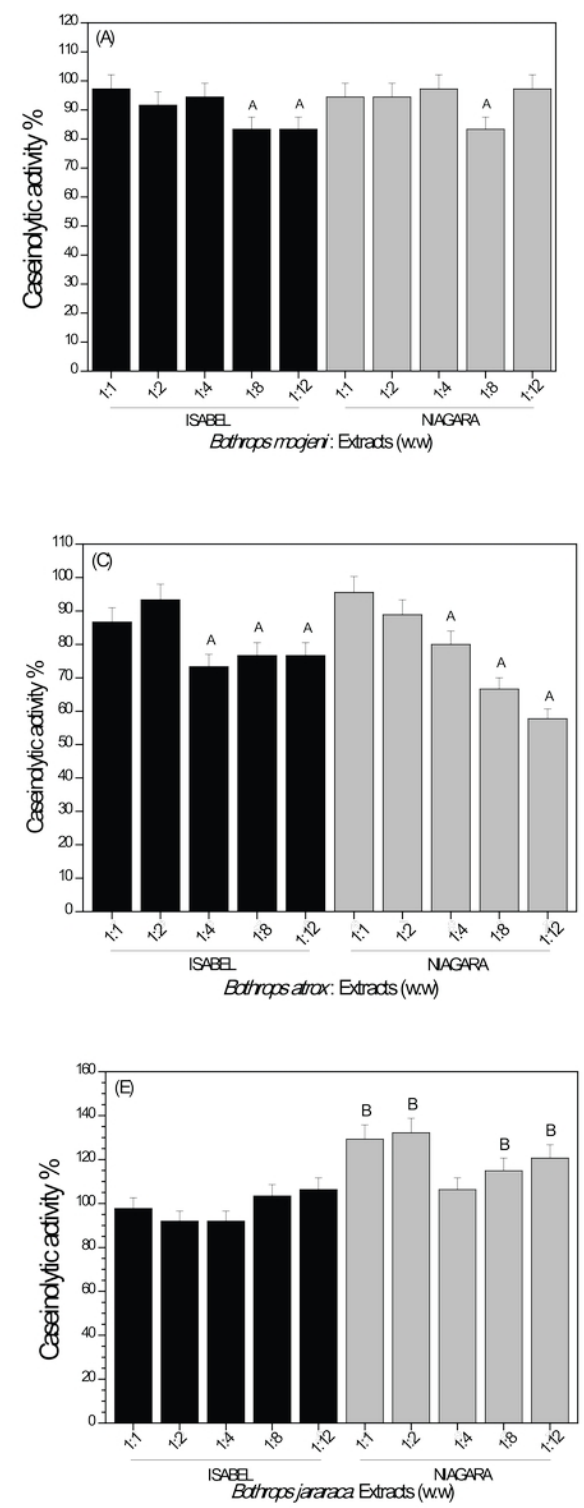
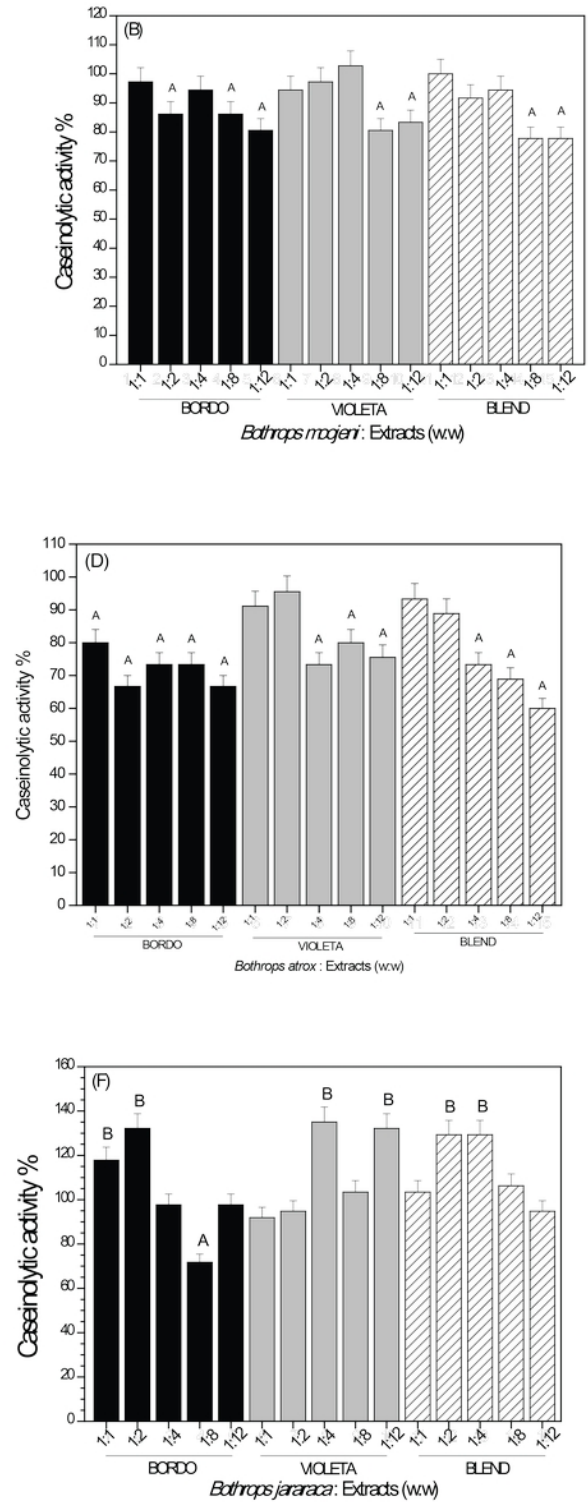

(2) (1)

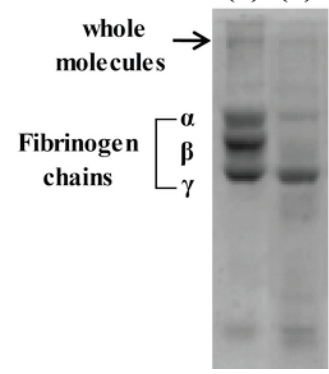

FIGURE 1 - Proteolysis activities. Effect of dried grape pomace from different cultivars on venom induced caseinolytic activity of Bothrops moojeni (A and B), B. atrox (C and D) and B. jararaca venoms (E and F). Controls $(+)$ containing only venom $(30$ $\mu \mathrm{g}$ ) were considered as $100 \%$ activity. $\mathrm{A}=$ differs from the positive control in inhibition. $\mathrm{B}=$ differs from the positive control in potentiation. Illustrative figure of the effect of dried grape pomace from different cultivars on the venom induced fibrinogenolytic activity of B. moojeni and B. atrox $(60 \mu \mathrm{g})(\mathrm{G})$. Previously incubated with fibrinogen $(60 \mu \mathrm{g})$ alone or in the presence of dried pomace evaluated in ratios 1: 4 and 1: 8 (w: w). (1) $\alpha, \beta$ and $\gamma$ chains of widely fragmented fibrinogen molecules in the presence of pure venom. (2) $\alpha, \beta$ and $\gamma$ chains of intact fibrinogen molecules after incubation of grape extract with venom. 
proteolytic and fibrinogenolytic activities induced by Thai snake and Malayan pit viper venoms. The authors suggest that phenolic compounds formed hydrogen bonds with histidine residues at the zinc binding site exerting chelating action on the cofactors of venom metalloproteases. The same mechanism may be suggested for the present study in which Niagara dried pomace presented the lowest content of phenolic compounds (Table I) and lower inhibitory activity on $B$. moojeni venom (Figure 1A).

According to Gómez-Betancur et al. (2014) Renealmia alpinia extract in the ratio 1:20 inhibited the proteolytic activity induced by $B$. asper venom in $88.53 \%$, while the isolated compound, pinostrobin, with the same proportion exhibited inhibition of $21.86 \%$. In addition, Casearia sylvestris leaf extract inhibited the proteolytic activity induced by different Bothrops snake venoms and by the isolated metalloproteases of $B$. asper in approximately $80 \%$, in the ratios 1:10 and 1:5 (Borges et al., 2001). The same author suggests that the extracts work as natural chelators, interacting with metallic ions, although the synergism between the molecules of the extract may contribute to its activity.

The potentiating effect of the proteolytic activity exerted by Niagara, Bordô, Violeta and Blend dried pomace, when incubated with the $B$. jararaca venom (Figure $1 \mathrm{E}$ and $\mathrm{F}$ ), suggests the presence of indirect interaction of cofactors made available by the extracts, promoting an increase in activity of venom proteases. This can be observed considering the Niagara dried pomace which presented the highest mineral content and one of the lowest phenolic compounds contents (Table I), and the Isabel dried pomace which presented the lowest mineral content and did not exert a potentiating effect on the proteolysis activity. However, additional studies are needed to elucidate the interactions between plant compounds and proteolysis enzymes since the action of these compounds alone or in synergism possibly occurs through several mechanisms.

For the activity on blood thrombi, the dried pomace exerted both thrombotic and thrombolytic action. Blend, Violeta, Bordô and Niagara dried pomace exhibited thrombolytic activity, in most of the evaluated ratios, potentiating the dissolution of the thrombi induced by Lachesis muta muta venom (Figure 2A and B). It is suggested that the components of the dried pomace may interact with the active sites of the proteases present in the venoms, by means of covalent or non-covalent bonds, preventing the binding of the substrate, and therefore inhibiting the enzymatic activity (Borges et al., 2001) and consequently other enzyme-dependent actions of the enzymatic activity.

In fact, Niagara and Bordô dried pomace with 1:4 ratios were able to completely dissolve the thrombus formed. However, Isabel dried pomace, acting on the same venom, showed thrombotic activity, in ratios 1:2 and 1:8 (Figure 2A).

The thrombolytic activity of the $B$. moojeni venom was inhibited by all dried pomace, with variations related to the proportions evaluated. In the present study, the Niagara and Blend dried pomace were able to inhibit thrombolytic activity with values greater than $100 \%$ (Figure 2C and D), in relation to the negative control (PBS), evidencing its thrombotic action.

The action of the pure dried pomace on the thrombi was also analyzed, and all presented values of volumes of released liquid lower than those obtained in the control containing only PBS (data not shown), confirming the thrombotic activity exerted by dried pomace rich in phenolic compounds.

The inhibition of thrombolytic activity induced by venoms through the dried pomace evaluated may be related to the ability to inhibit thrombin enzymes, serine proteases, which have structure and function similar to thrombin, suggesting possible pharmaceutical applications. The hemorrhagic effect of thrombin is promoted by the depletion of fibrinogen molecules caused by accelerating the production of fibrin with unconventional structure and is responsible for the formation of friable clots (Sajevic et al., 2011).

The inhibitory and potentiating actions of the thrombolytic effects exerted by the dried pomace can also occur independently of the interaction with the venom. According to Kwon et al. (2016), Vitis vinifera leaf extract presented flavonoids such as quercetin, isorhamnetine and rutin and exhibited anti-platelet activity by the suppression of Tromboxane B2 and serotonin. In view of this, grape extracts can act in the stages of blood coagulation, affecting hemostasis, as found in this work.

In addition, studies with Agastache rugosa extracts demonstrated procoagulant activity, whereas compounds isolated from the same species, acacetin and tilanin, had anticoagulant effects (Cao et al., 2017). Thus, the different compounds Isabel, Niagara, Bordô, Violeta and Blend dried pomace can also act in different targets resulting in induction of coagulation and thrombotic action or disintegration of platelets and 

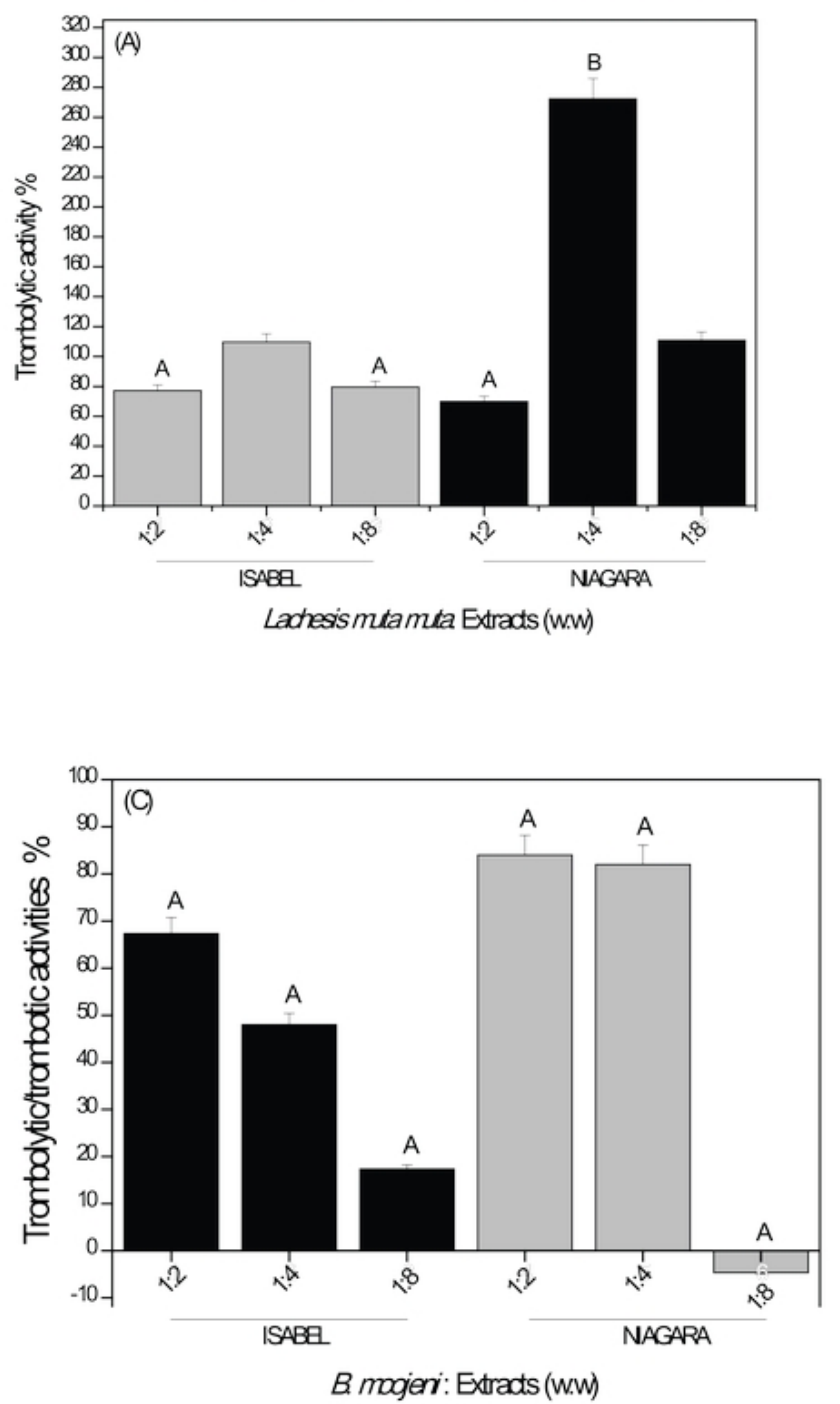
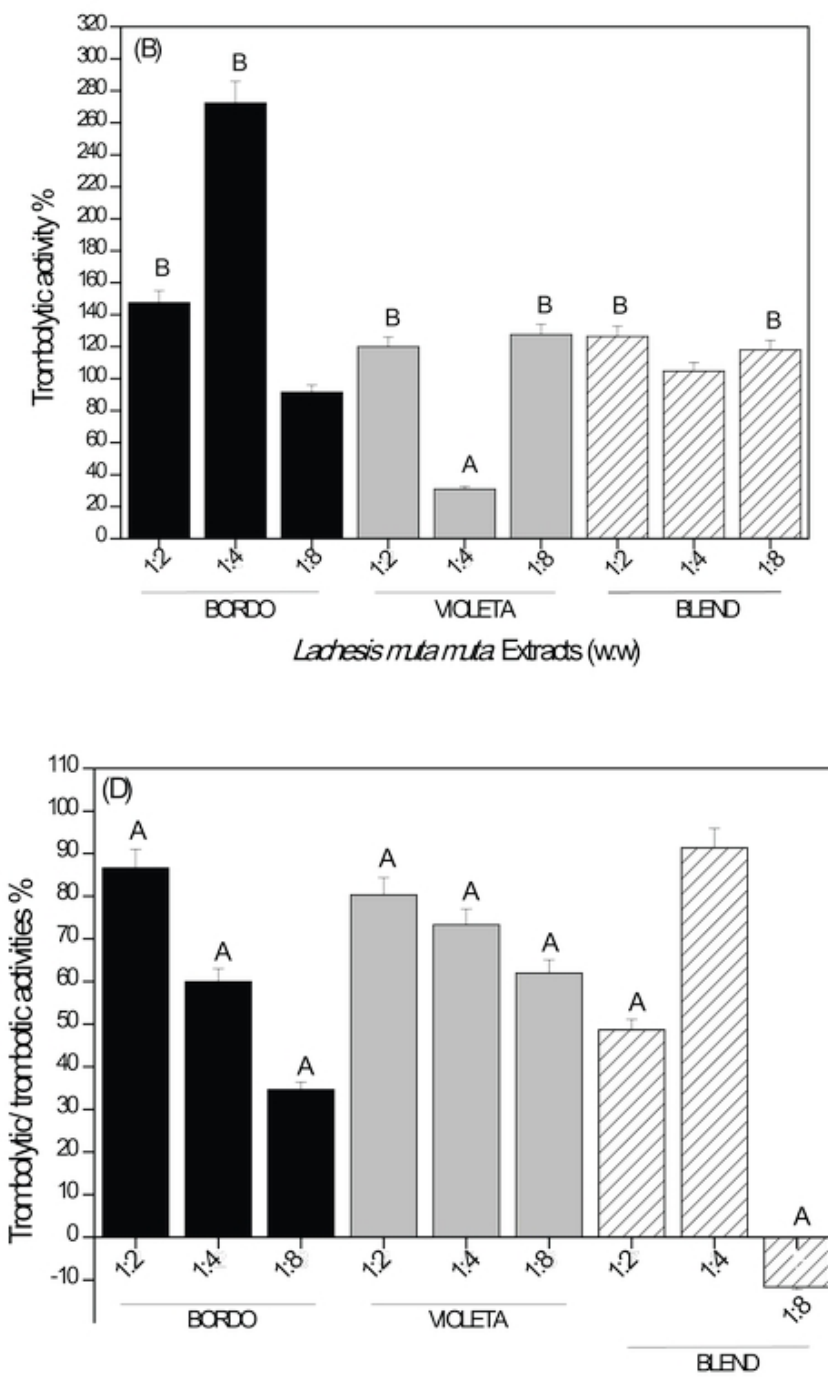

B. mogien: Extrads (w.w)

FIGURE 2 - Effect of dried grape pomace from different cultivars on venom-induced thrombolytic activity of Lachesis muta muta (A and B) and Bothrops moojeni venoms (C and D). The data represent means and standard deviation of values obtained in three independent tests performed with samples evaluated in triplicate. Controls $(+)$ containing only venom $(30 \mu \mathrm{g})$ were considered as $100 \%$ activity. $\mathrm{A}=$ differs from the positive control in inhibition. $\mathrm{B}=$ differs from the positive control in potentiation.

disarrangement of the coagulation cascade factors and thrombolytic action. Thus, complementary studies are needed to elucidate the mechanisms of action of these isolated compounds and also of the pure dried pomace for safe and effective use, allowing the application of industrial waste in various therapies.

Isabel and Niagara dried pomace in the proportions $1: 5$ and $1: 1$, respectively, were able to inhibit the phospholipase activity of the $B$. atrox venom, however, the lower ratios evaluated for Bordô, Violeta and Blend dried pomace potentiated this activity (Figure 3A).
Phospholipase activity induced by the $B$. jararaca venom did not change in the presence of the Isabel and Blend dried pomace, but the Niagara, Bordô and Violeta dried pomace enhanced this activity (Figure 3B). For $B$. jararacussu venom, this activity was inhibited after incubation with Niagara (1:10), Blend (1:5, 1:10 and $1: 20)$ and Violeta (1:10 and 1:20) dried pomace, but the Violeta dried pomace in lower proportions increased the phospholipid breakage. Isabel and Bordô dried pomace did not significantly alter the action of phospholipases present in B. jararacussu venom (Figure 3C). 

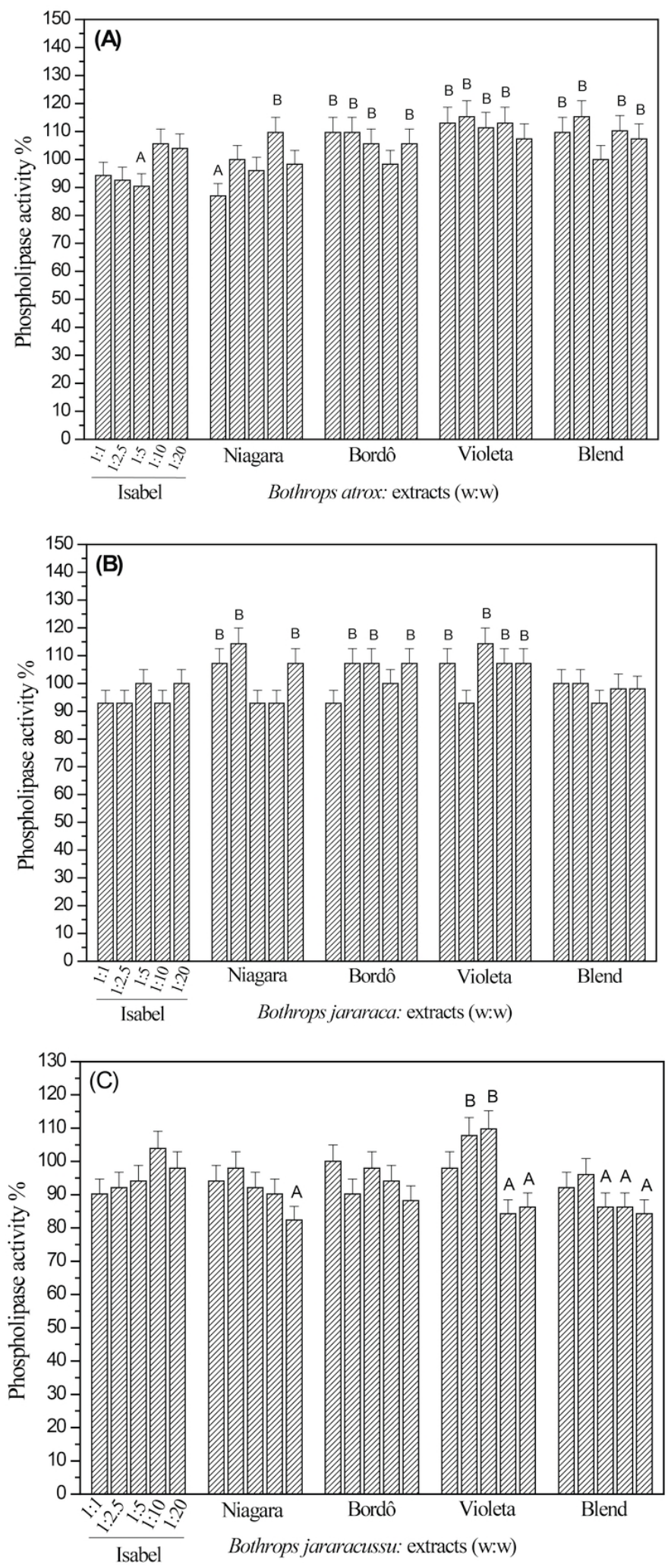

FIGURE 3 - Effect of dried grape pomace from different cultivars on venom induced phospholipase activity of Bothrops atrox (A), B. jararaca (B) and B. jararacussu venoms (C). The data represent means and standard deviation of values obtained in three independent tests performed with samples evaluated in triplicate. Controls $(+)$ containing only venom $(30 \mu \mathrm{g})$ were considered as $100 \%$ activity. $\mathrm{A}=$ differs from the positive control in inhibition. $\mathrm{B}=$ differs from the positive control in potentiation. 
In the higher ratios, the Bordô, Violeta and Blend dried pomace inhibited the hemolytic activity induced by the $B$. moojeni venom; however, Isabel dried pomace potentiated this activity in a ratio of $1: 0.5$ and inhibited in a ratio of $1: 4$, while the Niagara dried pomace exerted only a potentiating effect in the ratio of 1:4. For B. jararacussu venom, this activity was potentiated after incubation with Niagara dried pomace in all ratios evaluated, Violeta (1:0.5 and 1:1) and Isabel (1:5) and inhibited after incubation with Blend (1:0.5 and 1:1), Violeta (1:2.5 and 1:5) and Isabel (1:0.5, 1:1 and 1:2.5) dried pomace. Bordô dried pomace showed no effect on hemolysis induced by $B$. jararacussu venom (Figure 4B).

Isolated compounds of Schizolobium parahyba leaf, myricetin-3-O-glycoside and gallocatechin inhibited the hemorrhagic and fibrinogenolytic activities induced by Bothrops metalloproteases (Vale et al., 2011). In addition, Renealmia alpinia extracts were able to inhibit the enzymatic, hemorrhagic and fibrinogenolytic activities induced by Batx-I metalloprotease, isolated from $B$. asper venom (Patiño et al., 2013). These latter authors suggest a molecular interaction between the phenolic compounds and the proteases present in the venoms. In the present study, Bordô, Violeta and Blend dried pomace presented the highest contents of phenolic compounds (Table I) and inhibitory effects on the hemolytic activity induced by B. moojeni venom (Figure 4A). However, the amount and type of compounds present in each dried pomace and the action alone or in synergism exerted by these molecules on the different classes of enzymes present in the venoms, should be more widely studied.

\section{CONCLUSION}

Dried grape pomace obtained from Isabel, Niagara, Bordô, Violeta and Blend cultivars have effects on proteolytic enzymes, giving them therapeutic potential with possible preventive and curative application in pathological processes related to the gastrointestinal tract. Phenolic compounds may be the main responsible for the inhibitory action exerted on proteolysis activity. However, complementary studies are necessary to elucidate the interactions of these natural compounds with metalloproteases and serine proteases, present in snake venoms, and highly homologous to human enzymes. In addition, the inhibition of phospholipases can be exploited aiming at anti-inflammatory actions related to the inhibition of these enzymes with consequent reduction in the production of eicosanoids. The determination of the phenolic composition of these industrial residues from the processing of grapes will allow their use, whether for nutraceutical, pharmacological or cosmetic purposes. However, considering the various actions of the dried pomace observed in the present study, inhibiting or potentiating enzyme activities, new studies should be conducted with a view to the definition of doses, formulations and administration forms suitable for human use in an efficient and safe manner.

\section{ACKNOWLEDGMENTS}

This work was supported by the Conselho Nacional de Desenvolvimento Científico e Tecnológico (CNPq), Fundação de Amparo a Pesquisa do Estado de Minas Gerais (FAPEMIG), Coordenação de Aperfeiçoamento de Nível Superior (CAPES).

\section{CONFLICT OF INTEREST}

On behalf of all authors, the corresponding author states that there is no conflict of interest. 

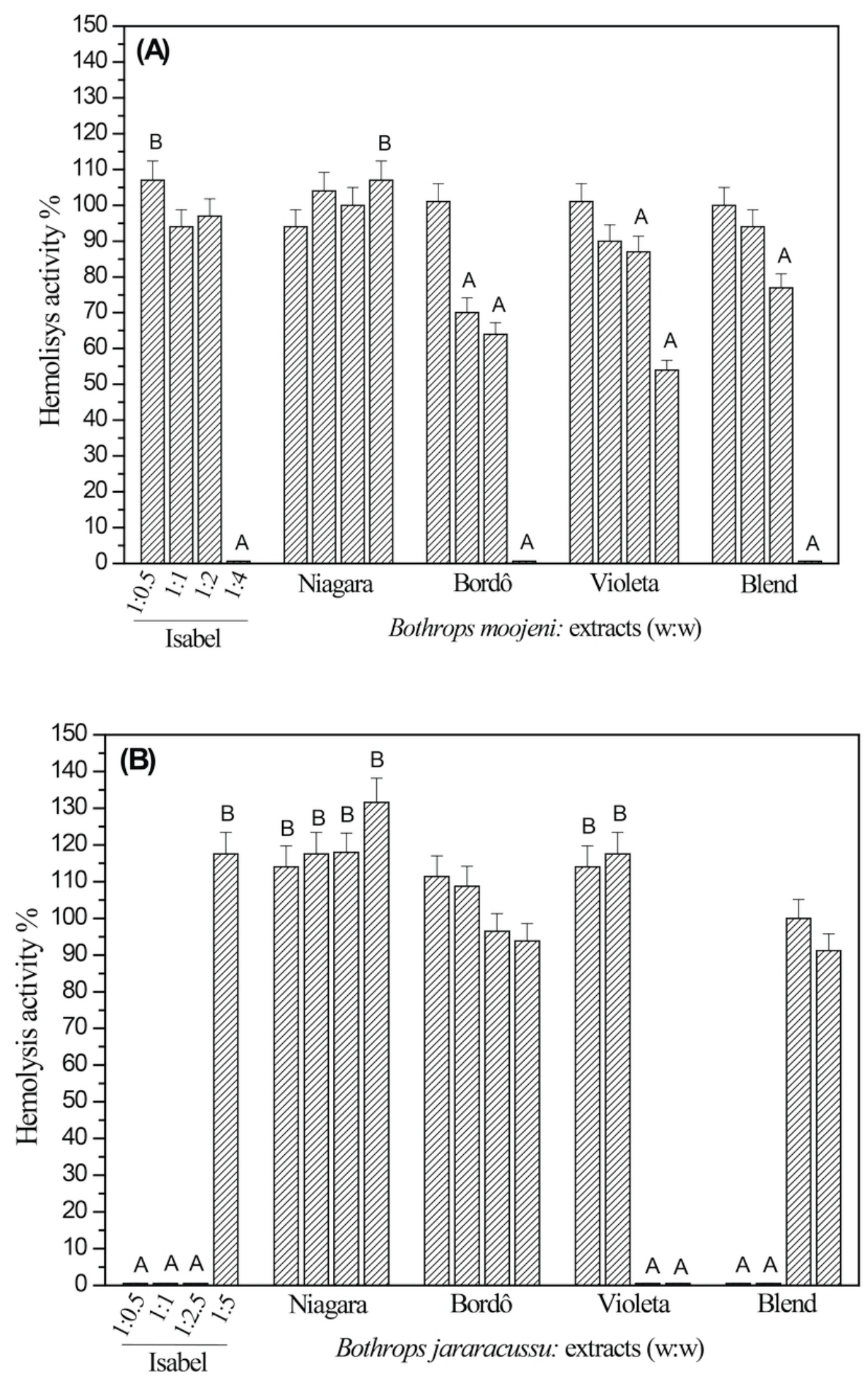

FIGURE 4 - Effect of dried grape pomace from different cultivars on venom-induced hemolytic activity of Bothrops moojeni (A) and $B$. jararacussu venoms (B). The data represent means and standard deviation of values obtained in three independent tests performed with samples evaluated in triplicate. Controls $(+)$ containing only venom $(30 \mu \mathrm{g})$ were considered as $100 \%$ activity. $\mathrm{A}=$ differs from the positive control in inhibition. $\mathrm{B}=$ differs from the positive control in potentiation. 


\section{REFERENCES}

Abe LT, da Mota RV, Lajolo FM, Genovese MT. Compostos fenólicos e capacidade antioxidante de cultivares de uvas Vitis lambrusca L. e Vitis vinifera L. Ciênc Tecnol Aliment. 2007;27(2):394-400.

Alam MI, Alam MA, Alam O, Nargotra A, Taneja SC, KoulS. Molecular modeling and snake venom phospholipase $\mathrm{A}_{2}$ inhibition by phenolic compounds: structure-activity relationship. Eur J Med Chem. 2016;114:209-219.

Ali K, Maltese F, Choi Y, Verpoorte R. Metabolic constituents of grapevine and grape-derived products. Phytochem Rev 2010;9(3):357-378.

Babbar N, Oberoi HS, Uppal DS, Patil RT. Total phenolic content and antioxidant capacity of extracts obtained from six important fruit residues. Food Res Int. 2011;44(1):391-396.

Berling I, Isbister GK. Hematologic effects and complications of snakeenvenoming. Transfus Med Rev. 2015;29(2):82-89.

Birrel GW, Earl STH, Wallis TP, Masci PP, Jersey J, Gorman $\mathrm{JJ}$, et al. The diversity of bioactive proteins in Australian snake venom. Mol Cell Proteomics.2007;6(6):973-983.

Bjarnason JB, Fox JW. Hemorrhagic metalloproteinases from snake venoms. Pharmacol Therapy. 1994;62(3):325-372.

Borges MH, Soares AM, Rodrigues VM, Oliveira F, Fransheschi AM, Rucavado A, et al. Neutralization of proteases from Bothrops snake venoms by the aqueous extract from Casearia sylvestris (Flacourtiaceae). Toxicon. 2001;39(12):1863-1869.

Botella C, Diaz A, Ory I, Webb C, Blandino A. Xilanase and pectinase production by Aspergillus awamori on grape pomace in solid state fermentation. Proc Biochem. 2007;42(1):98-101.

Bozan B, Tosun G, Ozcan D. Study of polyphenol content in the seeds of red grape (Vitis vinifera $\mathrm{L}$.) varieties cultivated in Turkey and their antiradical activity. Food Chem. 2008;109:426-430.

Branan RG. Effect of grape seed extract on physicochemical properties of ground, salted, chicken thigh meat during refrigerated storage at different relative humidity levels. J. Food Science. 2008;73(1):36-40.

Cantos E, Espín JC, Tomás-Barberán FA. Varietal differences among the polyphenol profiles of seven table grape cultivars studied by LC-DAD-MS-MS. J. Agric. Food Chem. 2002;50:5691-5696.
Cao P, Xie P, Wang X, Wang J, Wei J, Kang WJ. Chemical constituents and coagulation activity of Agastache rugosa. BMC Complement Altern Med. 2017;17(1):93.

Capanoglu E, de Vos RCH, Hall RD, Boyacioglu D, Beekwilder J. Changes in polyphenol content during production of grape concentrate. Food Chem. 2013;20:526-539.

Cintra AC, de Toni LG, Sartim MA, Franco JJ, Caetano RC, Murakami MT, et al. Batroxase, a new metalloproteinase from Bothrops atrox snake venom with strong fibrinolytic activity. Toxicon. 2012;60(1):70-82.

Farhadi K, Esmaeilzadeh F, Hatami M, Forough M, Molaie R. Determination of phenolic compounds content and antioxidant activity in skin, pulp, seed, cane and leaf of five native grape cultivars in West Azerbaijan province, Iran. Food Chem. 2016;199(5):547-855.

Fontana AR, Antoniolli A, Bottini R. Grape pomace as a sustainable source of bioactive compounds: extraction, characterization, and biotechnological applications of phenolics. J Agric Food Chem. 2013;61(38):8987-9003.

Georgiev V, Ananga A, Isolova V. Recent advances and uses of grape flavonoids as nutraceutcials. Nutrients. 2014;6(1): 391-415,

Gómez-Betancur I, Benjumea P, Patiño A, Jimenez N, Osorio E. Inhibition of the toxic effects of Bothrops asper venom by pinostrobin, a flavanone isolated from Renealmia alpinia (Rottb.) MAAS. J. Ethnopharmacol. 2014;155(3):1609-1615.

Gutiérrez J, Avila CR, Cerdas L. An alternative in vitro method for testing the potency of the polyvalent antivenom produced in Costa Rica. Toxicon.1988;26(4):411-413.

Kammoun R, Naili B, Bejar S. Application of a statistical design to the optimization of parameters and culture medium for -amylase production by Aspergillus oryzae CBS 819.72 grown on gruel (wheat grinding by-product). Bioresour Technol. 2008;99(13):5602-5609.

Kwon SU, Lee HY, Xin M, Ji SJ, Cho HK, Kim DS, et al. Antithrombotic activity of Vitis labrusca extract on rat platelet aggregation. Blood Coagul Fibrinolysis. 2016;27(2):141-146.

Laemmli UK. Cleavage of structural proteins during the assembly of the head of bacteriophage T4. Nature. 1970;227:680-685.

Leanpolchareanchai J, Pithayanukul P, Bavovada R, Saparpakorn P. Molecular docking studies and anti-enzymatic activities of Thai mango seed kernel extract against snake venoms. Molecules. 2009;14(4):1404-1422. 
Mahadeswaraswamy YH, Nagaraju S, Girish KS, Kemparaju $\mathrm{K}$. Local tissue destruction and procoagulation properties of Echis carinatus venom: inhibition by Vitis vinifera seed methanol extract. Phytother Res. 2008;22(7):963-969.

Malavolta E. Avaliação do estado nutricional de plantas: princípios e aplicações. Piracicaba: Potafos; 1997. 308 p.

Mello LMR, Silva GA. Disponibilidade e características de resíduos provenientes da agroindústria de processamento de uva do Rio Grande do Sul. Comunicado Técnico. Embrapa Uva e Vinho. 2014;155:1-6.

Miele A, Rizzon LA, Zanotto DL. Free amino acids in Brazilian grape juices. Riv Vitic Enol. 1990;43(4):15-21.

Negro C, Tommasi L, Miceli A. Phenolic compounds and antioxidant activity from red grape marc extracts. Bioresource Technology. 2003;87(1):41-44.

Oliveira CHM, Simão AA, Marcussi S. Inhibitory effects of ascorbic acid, vitamin $\mathrm{E}$ and vitamin B-complex on the biological activities induced by Bothrops venom. Pharm Biol. 2015;54(5):845-852.

Organização das Nações Unidas para a Alimentação e Agricultura. [citad 2016 Nov 11]. Available from: < http:// www.fao.org/brasil/pt/>.

Patiño AC, Benjumea DM, Pereañez JA. Inhibition of venom serine proteinase and metalloproteinase activities by Renealmia alpinia (Zingiberaceae) extracts: Comparison of wild and in vitro propagated plants. J Ethnopharmacol. 2013;149(2):590-596.

Pereañez JA, Nunez V, Patiño, AC, Londono M, Quintana JC. Inhibitory effects of plant phenolic compounds on enzymatic and cytotoxic activities induced by a snake venom phospholipase $A_{2}$. Vitae. 2011;18(3):295-304.

Pithayanukul P, Leanpolchareanchai J, Saparpakorn P. Molecular docking studies and anti- snake venom metalloproteinase activity of Thai mango seed kernel extract. Molecules. 2009;14(9):3198-3213.

Rufino MSM, Alves RE, Brito ES, Mancini-Fillho J, Moreira AVB. Metodologia Científica: Determinação da atividade antioxidante total em no sistema beta-caroteno/ácido linoleico. Comunicado Técnico: Embrapa Fortaleza. 2006: 4p.
Rufino MSM, Alves RE, Brito ES, Morais SM, Sampaio CG, Perez-Jimenez J, Saura-Calixto FD. Metodologia Científica: Determinação da atividade antioxidante total em frutas pela captura do radical livre DPPH. Comunicado Técnico: Embrapa Fortaleza. 2007: 4p.

Rockenbach IV, Gonzaga LV, Rizelio VM, Gonçalves AESS, Genovese MI, Felt R. Phenolic compounds and antioxidant activity of seed and skin extracts of red grape (Vitis vinifera and Vitis labrusca) pomace from Brazilian winemaking. Food Res International. 2011;44(4):897-901.

Sajevic T, Leonardi A, Križaj I. Haemostatically active proteins in snake venoms. Toxicon. 2011;57(5):5627-645.

Singleton VL, Rossi JA. Colorimetry of total phenolics with phosphomolybidic-phosphotungstic acid reagent. Am J Enol Vitic.1965;16:144-158.

Soares M, Welter L, Kuskoski EM, Gonzaga L, Felt R. Compostos fenólicos e atividade antioxidante da casca de uvas Niágara e Isabel. Rev Bras Fruticul. 2008;30(1):59-64.

Sun B, Spranger MI. Review: Quantitative extraction and analysis of grape and wine proanthocyanidin and stilbenes. Ciência Tec Vitiv. 2005;20:59-89.

Strauch MA, Tomaz MA, Monteiro-Machado M, RicardoHD,Cons B, Fernandes FF, et al. Antiophidic activity of the extract of the Amazon plant Humirianthera ampla and constituents. J Ethnopharmacol. 2013;145(1):50-58.

Vale HM, Mendes MS, Fernandes RS, Costa TR, HageMelim LI, Sousa M, et al. Protective effect of Schizolobium parahyba flavonoids against snake venoms and isolated toxins. Curr Top Med Chem. 2011;11(20):2566-2577.

Van Der Walt SJ, Joubert FJ. Studies on puff adder (Bitis arietans) venom-I, purification and properties of protease A. Toxicon. 1971;9(2):153-161.

Vilas Boas AC, Henrique PC, Lima LCO, de Carlos Neto A. Antioxidant activity, anthocyanins and organic acids content of grape juices produced in southwest of Minas Gerais, Brazil. Ciênc Agrotecnol. 2014;38(5):480-486.

Received for publication on $24^{\text {th }}$ November 2018 Accepted for publication on $11^{\text {st }}$ March 2019 